\title{
Effects of glucose and glucose-insulin-potassium on haemodynamics and enzyme release after acute myocardial infarction
}

\author{
M. K. HENG, R. M. NORRIS, B. N. SINGH, AND CARAN BARRATT-BOYES
}

From the Departments of Coronary Care and Cardiology, Green Lane Hospital, and the Department of Medicine, University of Auckland School of Medicine, Auckland, New Zealand

The effects on haemodynamics and infarct size (measured by total creatine kinase release) of intravenous infusions of normal saline, glucose, or glucose-insulin-potassium were studied in 36 patients with transmural acute myocardial infarction of less than 12 hours' duration. In 12 patients, $2 \mathrm{ml} / \mathrm{kg} 50$ per cent glucose $(5.55 \mathrm{mmol} / \mathrm{kg}$ ) was given over 10 minutes with 0.4 unit $/ \mathrm{kg}$ soluble insulin 5 minutes later, followed by an infusion of $1.5 \mathrm{ml} / \mathrm{kg}$ per $\mathrm{hr}$ of 50 per cent glucose $(4.2 \mathrm{mmol} / \mathrm{kg} \mathrm{per} \mathrm{hr})$ containing 0.3 unit $/ \mathrm{kg}$ insulin and $0.15 \mathrm{mmol} / \mathrm{kg}$ potassium chloride. Similar volumes of 50 per cent glucose alone or normal saline alone were administered to 9 and 15 patients, respectively. Cardiac output and right heart pressures were measured in 28 patients by Swann-Ganz thermodilution catheter, and arterial pressure by an indwelling plastic cannula. Calculation of total enzyme release from serial creatine kinase measurements was made using individualised figures for the enzyme degradation rate.

Saline infusion had no significant effect on cardiovascular haemodynamics. Glucose did not affect heart rate, but increased mean arterial pressure and pulmonary artery diastolic pressure by 18 per cent $(P<0.001)$ and 42 per cent $(P<0.001)$ at 30 minutes and by 14 per cent $(P<0.005)$ and 25 per cent $(P<0.005)$ at 60 minutes after infusion, respectively. Glucose-insulin-potassium increased heart rate $(+13 \% ; P<0.05)$, mean arterial pressure $(+15 \% ; P<0.01)$, and pulmonary artery diastolic pressure $(+27 \% ; P<0.005)$ at 30 minutes but not at 60 minutes. Glucose increased cardiac index 22 per cent $(P<0.05)$ at 60 minutes; glucose-insulin-potassium increased cardiac index by 26 per cent $(P<0.005)$ at 30 minutes and by 22 per cent $(P<0.001)$ at 60 minutes. There was no effect on systemic vascular resistance, but glucose and glucose-insulinpotassium enhanced left ventricular stroke work index by 17 per cent $(P<0.02)$ and 25 per cent $(P<0.02)$ at 30 minutes and by 27 per cent $(P<0.02)$ and 22 per cent $(P<0.005)$ at 60 minutes, respectively. The degree of improvement in haemodynamic functions induced by glucose and glucose-insulin-potassium were comparable. Though the data are limited, these changes were not associated with a favourable trend in enzyme release. Furthermore, in the glucose-insulin-potassium group, one patient died and another was successfully resuscitated from cardiac arrest; 2 patients died in the glucose group, while no serious complications occurred among patients in the saline group.

It was concluded that the improvement in haemodynamic functions produced by glucose and glucoseinsulin-potassium infusions in uncomplicated myocardial infarcts was not associated with an obvious beneficial effect on clinical status and infarct size assessed by enzyme release. Continuation of the trial was, therefore, not ethically justifiable.

In recent years, increasing attention has been focused on the possibility that myocardial damage after acute coronary occlusion might be reduced by

'Supported by the Medical Research Council and the National Heart Foundation of New Zealand and the Auckland Medical Research Foundation.

Received for publiration 13 December 1976 metabolic or pharmacological interventions. The use of glucose and glucose-insulin-potassium infusions is of particular interest on theoretical grounds. Whereas the normal heart muscle derives most of its energy from aerobic metabolism of free fatty acids (Ballard et al., 1960; Evans, 1964), anaerobic breakdown of glucose becomes the main 
source of energy in myocardial ischaemia (Morgan et al., 1961; Weissler et al., 1968). Provision of increased quantities of glucose (or reduced quantities of free fatty acids) to the ischaemic myocardium may thus promote anaerobic glycolysis and lead to enhanced myocardial function and survival (De Leiris et al., 1975). Infusions of glucose and glucose-insulin-potassium have been reported to reduce infarct size in dogs (Maroko et al., 1972), and to improve myocardial function in clinical as well as experimental studies (Austen et al., 1965; Majid et al., 1972). Though there have been trials of glucose-insulin-potassium in the prophylaxis of cardiac arrhythmias after acute myocardial infarction in man (Mittra, 1965; Sodi-Pollares et al., 1966; M.R.C. Working Party Report, 1968), the effects of this regimen on cardiac function and myocardial ischaemic damage in this clinical setting are still not clearly defined. We have, therefore, investigated the effects of glucose-insulinpotassium, glucose, and normal saline infusions on myocardial function and enzyme release in three comparable groups of patients admitted to the coronary care unit (CCU) with acute myocardial infarction.

\section{Subjects and methods}

PATIENT SELECTION

The purpose and details of the study were explained to all patients and their consent obtained. All patients studied had transmural myocardial infarcts judged on clinical features and confirmed by the presence of pathological $Q$ waves and/or ST segment elevation in the electrocardiogram. Patients with maximum chest pain lasting longer than 12 hours, valvular heart disease, cardiogenic shock, diabetes mellitus, cardiac arrhythmias apart from isolated ectopic beats, or heart failure as indicated by ventricular gallop, basilar râles, or interstitial oedema radiologically, were excluded. Cardiac stimulants or diuretics were not required in any patient during haemodynamic study. Thirty-six patients were considered suitable for admission into the trial and were randomised into 3 groups: 12 patients received glucose-insulin- potassium infusion; 9, 50 per cent glucose; and 15 had normal saline. The 3 groups were comparable with regard to age and sex (Table 1). The mean time from the onset of maximal symptoms to therapeutic intervention was similar in the 3 groups (approximately 8 hours, Table 1), but varied widely, from 4 to 14 hours, in individual cases.

\section{HAEMODYNAMIC MEASUREMENTS}

After admission, each subject had a chest $x$-ray, and a polyethylene cannula was inserted percutaneously into a vein in the left arm for intravenous infusion and for withdrawal of blood for estimation of myocardial infarct size by serial determinations of creatine kinase (CK) activity (Sobel et al., 1972; Norris et al., 1975). Haemodynamic measurements were made in 28 patients under aseptic conditions in a specially equipped room in the CCU. Diazepam, 5 to $10 \mathrm{mg}$ intravenously, was given on one occasion to all patients about 1 hour before haemodynamic measurements. The 8 other patients who were studied after completion of the haemodynamic trial had serial enzyme measurements only. For the haemodynamic studies an incision was made in the right antecubital fossa, and the brachial artery and a superficial cubital vein were isolated. Right heart pressures were obtained with a SwanGanz flow-directed thermodilution catheter which was also used for measuring cardiac output in conjunction with an Edwards 9500 computer, the injectate being $10 \mathrm{ml}$ ice-cold 5 per cent dextrose solution. Arterial blood pressure was measured with a short polyethylene cannula inserted into the brachial artery. All pressures were recorded using Statham P23Db transducers and an Electronics for Medicine DR8 photographic recorder.

\section{PROCEDURES}

Control measurements of mean and phasic pulmonary artery, pulmonary wedge (PAWP), right atrial (RAP) and brachial artery phasic and mean pressures (MAP) were taken. Cardiac output was measured in triplicate at 2-minute intervals and results averaged. All haemodynamic measurements were repeated 30 minutes later after which one of

Table 1 Clinical details of patients

\begin{tabular}{llll}
\hline & Saline & Glucose & Glucose-insulin-potassium \\
\hline No. of patients & $13 \mathrm{M}, 2 \mathrm{~F}$ & $8 \mathrm{M}, 1 \mathrm{~F}$ & $11 \mathrm{M}, 1 \mathrm{~F}$ \\
Age (y) & 55 (range 36 to 69) & 57 (range 32 to 68) & 55 (range 41 to 67) \\
Site of infarction & 11 inf., 4 ant. & 5 inf., 4 ant. & 7 inf., 5 ant. \\
Duration of symptoms to intervention & 7.5 hours (range 4 to 14) & 8 fhours (range 5 to 14) & 8 hours (range 4 to 11.5) \\
\hline
\end{tabular}

$M$, males; $F$, females; inf., inferior; ant., anterior. 
the following infusions was given:

(a) Glucose-insulin-potassium

Two $\mathrm{ml} / \mathrm{kg} 50$ per cent glucose $(5.55 \mathrm{mmol} / \mathrm{kg})$ was given intravenously over 10 minutes, followed 5 minutes later by $0.4 \mathrm{unit} / \mathrm{kg}$ soluble insulin (Burroughs Wellcome). This was followed immediately by an infusion of $1.5 \mathrm{ml} / \mathrm{kg}$ per $\mathrm{hr}$ of 50 per cent glucose $(4 \cdot 2 \mathrm{mmol} / \mathrm{kg}$ per $\mathrm{hr}$ ) to which 0.3 unit $/ \mathrm{kg}$ soluble insulin and $0.15 \mathrm{mmol} / \mathrm{kg}$ potassium chloride were added.

(b) 50 per cent Glucose

Two $\mathrm{ml} / \mathrm{kg} 50$ per cent glucose $(5.55 \mathrm{mmol} / \mathrm{kg})$ was given over 10 minutes followed by an infusion of $1.5 \mathrm{ml} / \mathrm{kg}$ per $\mathrm{hr}(4.2 \mathrm{mmol} / \mathrm{kg}$ per hr$)$.

(c) Normal saline

Two $\mathrm{ml} / \mathrm{kg}$ normal saline was given over 10 minutes, followed by an infusion of $1.5 \mathrm{ml} / \mathrm{kg}$ per $\mathrm{hr}(4.2 \mathrm{mmol} / \mathrm{kg}$ per $\mathrm{hr})$.

Haemodynamic measurements were made at 30 and 60 minutes after the start of each infusion, after which the arterial cannula and the Swann-Ganz catheter were removed. To investigate the effect of the infusions on infarct size as measured by serial $\mathrm{CK}$ estimations, the glucose-insulin-potassium and glucose infusions were continued for 6 hours (3 patients) or 12 hours (18 patients). Saline infusion, however, was stopped after haemodynamic measurements were completed. Blood was withdrawn 2hourly from the intravenous cannula for 6 or 12 hours (28 patients) for the estimation of serum glucose and potassium by a Technicon Autoanalyser, and 2 to 4 -hourly for 36 to 72 hours in all patients for the measurement of infarct size from serial estimation of serum CK activity. In our modification (Norris et al., 1975) of the method of Sobel and colleagues (Sobel et al., 1972), accuracy of the calculations of total enzyme release is improved by the use of individualised figures for the degradation rate $\left(K_{D}\right)$ of $C K$. Enzyme activity of the serial specimens was measured by the method of Rosalki (1967) using a Unicam SP-800 spectrophotometer at $340 \mathrm{~nm}$, and results were expressed as the total CK release $\left(\mathrm{Et}+\Sigma \mathrm{Edt} \mathrm{K}_{\mathrm{D}}\right.$ ) (Sobel et al., 1972) in IU per ml serum. Results were not accepted unless $K_{D}$ for $C K$ could be estimated within 95 per cent confidence limits of \pm 15 per cent (Norris et al., 1975).

Mean arterial pressure (MAP) was obtained by electronic integration; pulmonary artery end diastolic pressure (PADP) was obtained by averaging the values of the pressures over at least one respiratory cycle.

Student's $t$ test was used to evaluate the statistical significance of the results.

Left ventricular stroke work index (LVSWI) was calculated as follows (Crexells et al., 1973):

$$
\begin{aligned}
\text { LVSWI } & =(\text { MAP-PADP }) \\
& \times \frac{\text { Cardiac Index }\left(\mathrm{ml} / \mathrm{min} \text { per } \mathrm{m}^{2}\right)}{\text { Heart Rate }(\text { beats } / \mathrm{min})} \\
& \times 0.0144\left(\mathrm{~g} \mathrm{~m} / \text { beat per } \mathrm{m}^{2}\right) .
\end{aligned}
$$

\section{Results}

\section{MEASUREMENTS OF CARDIAC INDEX AND PULMONARY ARTERY END DIASTOLIC PRESSURE}

The reproducibility of cardiac output measurements with the thermodilution technique in our laboratory, as calculated by the variation about the mean of triplicate measurements, was $5 \pm 4$ per cent (mean $\pm 1 S D$ ). Pulmonary artery end diastolic pressure was used as an indirect measurement of left ventricular filling pressure, as technically satisfactory records of pulmonary artery wedge pressure were not obtained in all patients. The correlation coefficient of pulmonary artery end diastolic pressure with pulmonary wedge pressure in those patients in whom measurements of wedge pressure could be made was $r=0.91$ (61 comparisons in 18 patients).

\section{CLINICAL EFFECTS}

Of the 36 patients, 3 died in hospital ( 1 in the glucose-insulin-potassium group and 2 in the glucose group), while a fourth patient in the glucose-insulin-potassium group was successfully resuscitated from ventricular fibrillation 4 hours after entry to the trial, and while she was receiving the infusion. The patient in the glucose-insulinpotassium group who died had an anterior and inferior infarct, and developed acute right bundlebranch block 12 hours after completion of an uneventful haemodynamic study and infusion; subsequently total $\mathrm{CK}$ release was high at $5.2 \mathrm{IU} / \mathrm{ml}$, indicating that he had a large infarct, and he complained of slight nocturnal breathlessness requiring treatment with a diuretic. On the thirteenth day he collapsed with ventricular fibrillation after further chest pain, and resuscitation was unsuccessful. Two patients died suddenly while still receiving glucose infusions, 6 and 9 hours after the infusions were started; in both cases necropsy showed the presence of haemopericardium. The mechanism of death in 1 patient was ventricular fibrillation, and necropsy showed occlusion of the left anterior descending artery and anterior myocardial infarction with cardiac rupture and pericardial tamponade. The second patient died in 'acute pump failure' (Lown et al., 1967); necropsy showed occlusion of the left anterior descending artery, a haemorrhagic anterior infarct, and $150 \mathrm{ml}$ of blood clot in the pericardium. There was no definite evidence of cardiac rupture, 
and the amount of blood in the pericardial cavity was insufficient to have caused tamponade. Neither of these patients had clinical evidence of cardiac failure before their death, but both had high blood sugar levels of $48.3 \mathrm{mmol} / 1$ and $20 \mathrm{mmol} / 1$, respectively, at the time of cardiac arrest. No deaths occurred among the 15 patients who received normal saline.

The fourth patient, from the glucose-insulinpotassium group referred to above, also had an anterior infarct and was resuscitated from ventricular fibrillation 4 hours after the infusion started. The arrhythmia occurred while the infusion was still in progress, and immediately after the event, blood glucose and serum potassium were 13.1 $\mathrm{mmol} / 1$ and $4.3 \mathrm{mmol} / 1$, respectively. Because of the necessity for electrical defibrillation, figures for $\mathrm{CK}$ release were considered unreliable and not included in the analysis.

None of the other surviving patients had cardiac complications attributable to the infusions. In particular, no patient developed overt cardiac failure or an increase in chest pain. Most of the patients receiving the glucose and glucose-insulinpotassium infusions had a feeling of increased warmth accompanied by osmotic diuresis.

\section{HAEMODYNAMIC CHANGES}

Table 2 summarises the haemodynamic effects of saline, glucose, and glucose-insulin-potassium in 28 patients. The 2 measurements of each variable recorded at 30-minute intervals before infusion was started were not significantly different, and were averaged to provide the control data. For the three groups, the control data were found to be statistically comparable. Within each group, the duration of symptoms to intervention did not appear to affect changes in haemodynamic variables.

Saline infusion had no significant effect on the 4 haemodynamic variables which we measured, namely heart rate, mean arterial pressure, pulmonary artery end diastolic pressure, or cardiac index. In contrast, glucose infusion increased mean arterial pressure by 18 per cent $(P<0.001)$ at 30 minutes and by 14 per cent $(P<0.005)$ at 60 minutes, and increased pulmonary artery end diastolic pressure by 42 per cent $(P<0.001)$ at 30 minutes and 25 per cent $(P<0.005)$ at 60 minutes. Cardiac index also rose significantly at 60 minutes $(+22 \% ; P<0.05)$, but heart rate did not change. Infusion of glucose-insulin-potassium resulted in significant increases in heart rate $(13 \% ; P<0.05)$, mean arterial pressure $(15 \% ; \mathrm{P}<0.01)$, and pulmonary artery end diastolic pressure $(27 \%$; $\mathrm{P}<0.025$ ), at 30 but not at 60 minutes (Table 2). Cardiac index increased at 30 minutes $(26 \%$; $P<0.005)$ and at 60 minutes (22\%; $P<0.001)$. The haemodynamic effects of glucose and glucoseinsulin-potassium were thus similar with respect to mean arterial pressure, pulmonary artery end diastolic pressure, and cardiac index, with glucose-insulinpotassium having, in addition, a positive chronotropic response of borderline statistical significance.

Of the derived indices, systemic resistance was not affected by infusion of saline, glucose, or glucose-insulin-potassium. Left ventricular stroke work index was, however, increased significantly both by glucose and by glucose-insulin-potassium, the rise after glucose being 17 per cent $(P<0.02)$ at 30 minutes and 27 per cent $(P<0.02)$ at 60 minutes, and after glucose-insulin-potassium 25 per cent $(P<0.02)$ at 30 minutes and 22 per cent $(P<0.005)$ at 60 minutes after the start of the infusions.

Fig. 1 shows the effects of the 3 infusion regimens

Table 2 Haemodynamic effects of normal saline, glucose, and glucose-insulin-potassium in patients with acute myocardial infarction

\begin{tabular}{|c|c|c|c|c|c|c|c|c|c|}
\hline Haemodynamic variables & $\begin{array}{l}\text { Saline }(N= \\
C\end{array}$ & $\begin{array}{l}=12) \\
30 \min \end{array}$ & $60 \min$ & $\underset{C}{\text { Glucose }}(N$ & $\begin{array}{l}=8) \\
30 \mathrm{~min}\end{array}$ & $60 \mathrm{~min}$ & $\underset{C}{G l u c o s e-i n s u l}$ & $\begin{array}{l}\text { lin-potassium } \\
30 \mathrm{~min}\end{array}$ & $\begin{array}{l}(N=10) \\
60 \min \end{array}$ \\
\hline HR (beat/min) & $77 \pm 6$ & $\begin{array}{l}72 \pm 5 \\
\text { NS }\end{array}$ & $\begin{array}{l}74 \pm 4 \\
\text { NS }\end{array}$ & $72 \pm 5$ & $\begin{array}{l}75 \pm 4 \\
\text { NS }\end{array}$ & $\begin{array}{l}74 \pm 4 \\
\text { NS }\end{array}$ & $79 \pm 6$ & $\begin{array}{l}89 \pm 6 \\
P<0.05\end{array}$ & $\begin{array}{l}85 \pm 6 \\
\text { NS }\end{array}$ \\
\hline MAP (mmHg) & $93 \pm 5$ & $\begin{array}{l}91 \pm 6 \\
\text { NS }\end{array}$ & $\begin{array}{l}93 \pm 6 \\
\text { NS }\end{array}$ & $90 \pm 7$ & $\begin{array}{l}106 \pm 7 \\
P<0.001\end{array}$ & $\begin{array}{l}103 \pm 7 \\
P<0.005\end{array}$ & $85 \pm 4$ & $\begin{array}{l}98 \pm 7 \\
P<0.01\end{array}$ & $\begin{array}{l}93 \pm 7 \\
\text { NS }\end{array}$ \\
\hline PADP (mmHg) & $13 \pm 1$ & $\begin{array}{l}14 \pm 1 \cdot 5 \\
\text { NS }\end{array}$ & $\begin{array}{l}15 \pm 1.5 \\
\text { NS }\end{array}$ & $12 \pm 1$ & $\begin{array}{l}17 \pm 2 \\
P<0.001\end{array}$ & $\begin{array}{l}15 \pm 2 \\
P<0.02\end{array}$ & $11 \pm 1$ & $\begin{array}{l}14 \pm 1.5 \\
P<0.025\end{array}$ & $\begin{array}{l}12 \pm 2 \\
\mathrm{NS}\end{array}$ \\
\hline CI $\left(1 /\right.$ min per $\left.\mathrm{m}^{2}\right)$ & $2 \cdot 6 \pm 0 \cdot 2$ & $\begin{array}{l}2.5 \pm 0.2 \\
\text { NS }\end{array}$ & $\begin{array}{l}2 \cdot 6 \pm 0 \cdot 2 \\
\text { NS }\end{array}$ & $2 \cdot 6 \pm 0 \cdot 19$ & $\begin{array}{l}2 \cdot 9 \pm 0 \cdot 17 \\
\text { NS }\end{array}$ & $\begin{array}{l}3.1 \pm 0.28 \\
P<0.05\end{array}$ & $2 \cdot 6 \pm 0 \cdot 12$ & $\begin{array}{l}3.3 \pm 0.18 \\
P<0.005\end{array}$ & $\begin{array}{l}3.2 \pm 0.16 \\
P<0.001\end{array}$ \\
\hline SRI (units per $\mathrm{m}^{2}$ ) & $32 \cdot 7 \pm 2 \cdot 2$ & $\begin{array}{l}33 \cdot 5 \pm 2 \cdot 6 \\
\text { NS }\end{array}$ & $\begin{array}{l}32 \cdot 1 \pm 1 \cdot 7 \\
\text { NS }\end{array}$ & $33 \cdot 8 \pm 5 \cdot 0$ & $\begin{array}{l}35 \cdot 1 \pm 5 \cdot 0 \\
\text { NS }\end{array}$ & $\begin{array}{l}34 \cdot 6 \pm 5 \cdot 0 \\
\text { NS }\end{array}$ & $30 \cdot 9 \pm 1 \cdot 8$ & $\begin{array}{l}28 \cdot 5 \pm 2 \cdot 7 \\
\text { NS }\end{array}$ & $\begin{array}{l}28 \cdot 0 \pm 2 \cdot 6 \\
\text { NS }\end{array}$ \\
\hline LVSWI (g m/m² per beat) & $39 \cdot 8 \pm 4 \cdot 7$ & $\begin{array}{l}40 \cdot 3 \pm 5 \cdot 0 \\
\text { NS }\end{array}$ & $\begin{array}{l}39 \cdot 8 \pm 4 \cdot 7 \\
\text { NS }\end{array}$ & $43 \cdot 5 \pm 4 \cdot 1$ & $\begin{array}{l}50.9 \pm 3.1 \\
P<0.02\end{array}$ & $\begin{array}{l}55.4 \pm 4.9 \\
P<0.02\end{array}$ & $36 \cdot 3 \pm 3 \cdot 7$ & $\begin{array}{l}46.2 \pm 5.1 \\
P<0.02\end{array}$ & $\begin{array}{l}44 \cdot 8 \pm 5 \cdot 0 \\
P<0.005\end{array}$ \\
\hline
\end{tabular}



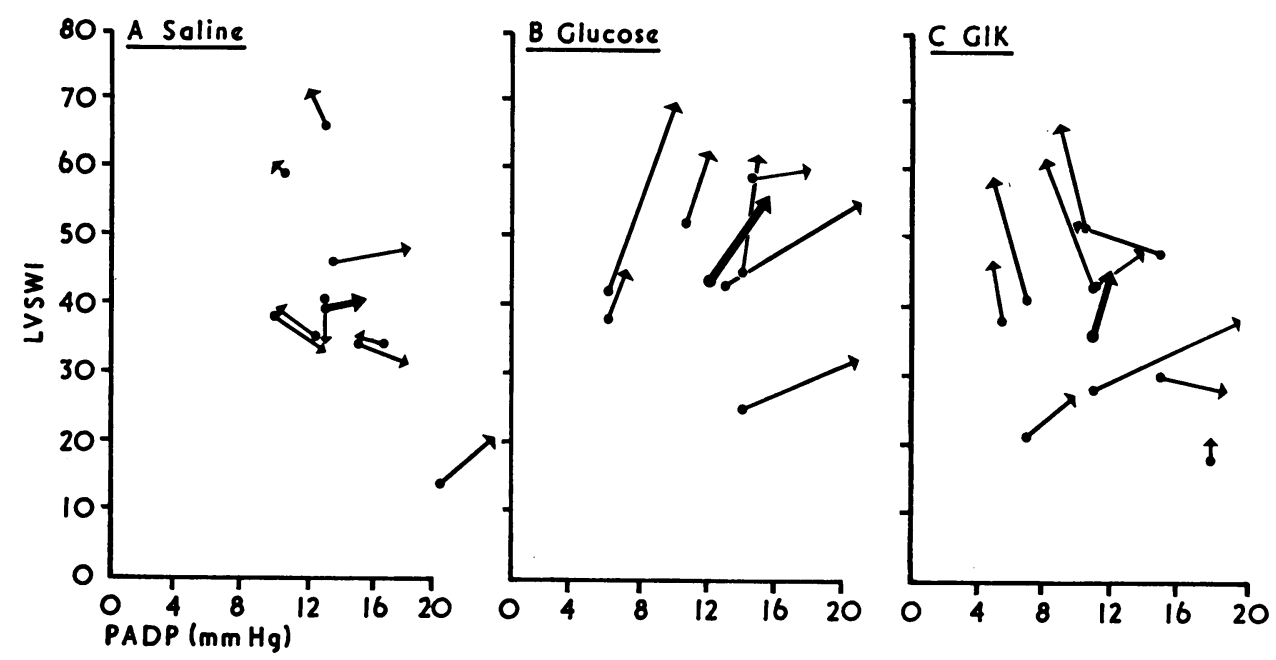

Fig. 1 Relation between pulmonary artery end diastolic pressure (PADP) and left ventricular stroke work index (LVSWI). The dots are control values, and the arrowheads are values 60 minutes after infusion. The thick lines are the mean values for each group, while the other lines represent individual patients.

on ventricular function as shown by plotting pulmonary artery end diastolic pressure (abscissa) against left ventricular stroke work index (ordinate) measured at 60 minutes after each intervention. It is apparent that in the case of glucose (panel B) and glucose-insulin-potassium (panel C), there were significant increases in left ventricular stroke work index associated with smaller increments in pulmonary artery end diastolic pressure. In contrast, in the saline group (panel A) only a slight increase in pulmonary artery end diastolic pressure occurred, with no effect on calculated left ventricular stroke work index.

\section{BIOCHEMICAL CHANGES}

The changes in blood glucose levels during the administration of the 3 regimens are presented in Fig. 2. The control values were similar in the 3 groups. In the saline group there was a slight and insignificant increase in the blood glucose over the next 12 hours. The blood glucose levels after glucose and glucose-insulin-potassium infusions were not significantly different, though a wide variation in levels among individual patients was noted. In these two groups, maximal levels of approximately $33.3 \mathrm{mmol} / 1$ were found during the first 4 hours.

Serum potassium levels (Fig. 2) were in general within normal limits during the period of infusion in the saline and glucose-insulin-potassium groups. In the glucose group, levels similar to those in the other 2 groups were found in the first 6 hours, but in the ensuing 6 hours a slight fall was noted.
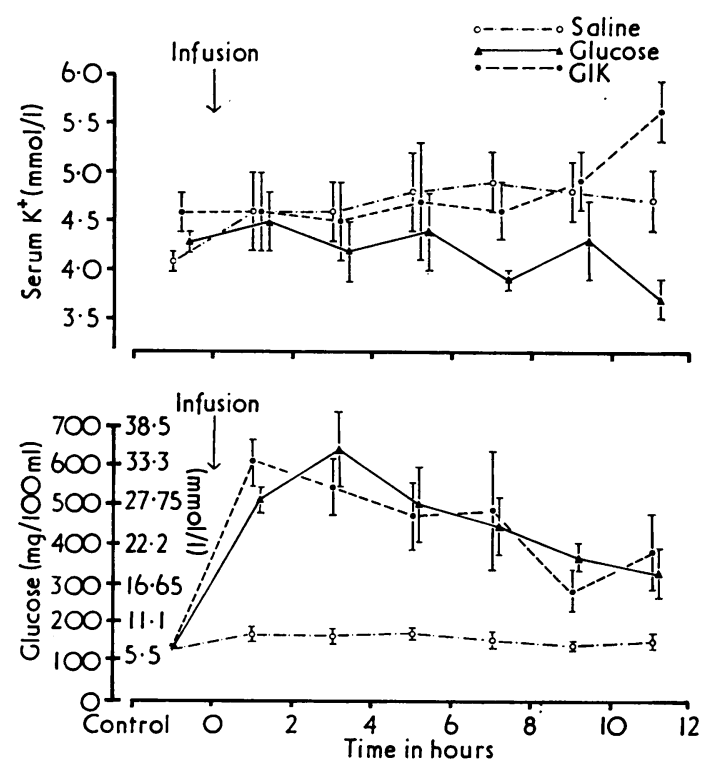

Fig. 2 Blood glucose and serum potassium levels before and after infusion. Mean $\pm 1 S E M$ for each group at 2-hourly intervals. Control blood glucose levels in the 3 groups were similar. 


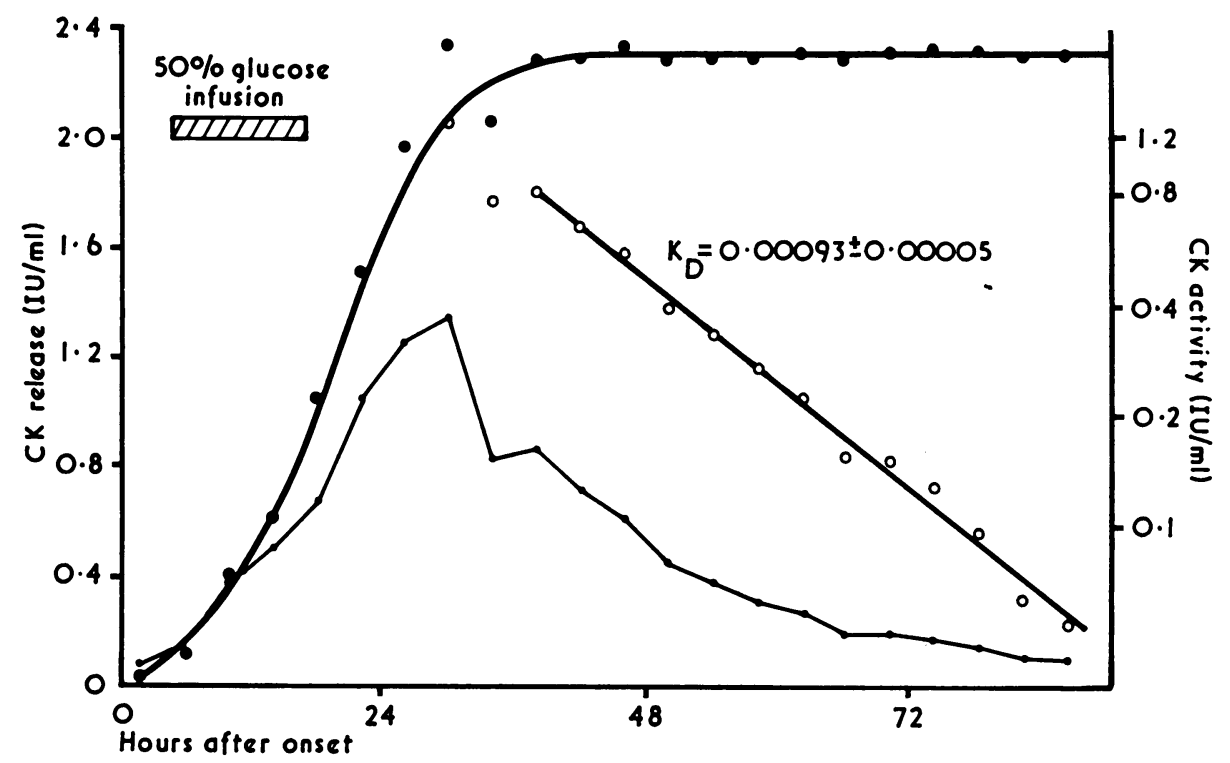

Fig. 3 Serum CK activity measurements in a patient who had infusion of 50 per cent glucose. Serial serum CK activity levels (small closed circles), and a semilogarithmic replot of the same levels from the peak of activity downwards (open circles) are shown, together with the calculated integrated appearance function ( $E t+K{ }_{\mathrm{D}} \Sigma E d t$, large closed circles) for each measurement. An assumed normal value of $0.04 \mathrm{IU} / \mathrm{ml}(40 \mathrm{mIU} / \mathrm{ml})$ has been subtracted from all measurements. The degradation rate $\left(K_{\mathrm{D}}\right)$ was calculated from 13 points on the descending level of $C K$ activity. In some cases (not in this example) the early part of the down-slope is omitted for the calculation of $K_{\mathrm{D}}$ because a slower rate of decline, as determined by visual inspection, might signify continuing release of CK from the infarct despite falling serum levels. Similarly in other examples the last part of the downslope (below about $200 \mathrm{mIU} / \mathrm{ml}$ ) is omitted because error caused by uncertainty about the precise normal level of CK activity for the patient under consideration increases as the activity approaches normal. The integrated appearance function (total CK release as calculated from the 4-hourly serum levels and the observed $K_{\mathrm{D}}$ ) is approximately $2.3 \mathrm{IU} / \mathrm{ml}$ in this patient, and enzyme release is complete at 35 to 40 hours after the onset of chest pain. The slope of the integral curve before this time is proportional to the velocity of enzyme release.

\section{CREATINE KINASE RELEASE}

Total CK release as measured by integral (ET+ $\Sigma \mathrm{Edt}_{\mathrm{D}}$ ) (Sobel et al., 1972; Norris et al., 1975) was determined in 30 of the 36 patients. The method used for calculation of the integral is summarised in Fig. 3. Reasons for failure to record the integral were early death before $K_{D}$ enzyme degradation could be measured ( 2 cases), the necessity for electrical defibrillation (1 case), unacceptably wide 95 per cent confidence limits for $\mathrm{K}_{\mathrm{D}}$ (Norris et al., 1975) (2 cases), and technical difficulties with venesection ( 1 case). The degradation rate $\left(K_{D}\right)$ for CK was not affected by glucose or glucoseinsulin-potassium. The mean $\mathrm{K}_{\mathrm{D}}$ for patients given saline was $0.00103 \pm 0.0039$ (SD) $\mathrm{min}^{-1}$, while for patients given glucose it was $0.00097 \pm 0.00020$ $\min ^{-1}$, and for patients given glucose-insulin potassium, $0.00106 \pm 0.00020 \mathrm{~min}^{-1}$.

Figures for total CK release are shown in Fig. 4; as we have previously noted (Norris et al., 1975), a wide scatter of values occurs, so that no significant differences were apparent among the 3 treatment groups. In addition, the duration of symptoms before intervention did not appear to bear on the value for total CK release within each group; we have also noted previously that calculation of the integral is not affected if the start of sampling is delayed for up to 12 hours after the onset of infarction.

There was a tendency for patients with inferior infarction treated with glucose or glucose-insulinpotassium to have larger infarcts (assessed by CK integral) than those treated with normal saline. The mean integral for patients treated with glucoseinsulin-potassium or glucose was $2 \cdot 1 \mathrm{IU} / \mathrm{ml}$ (SEM $0.4, n=10$ ), while for those treated with normal saline it was $1.3 \mathrm{IU} / \mathrm{ml}$ (SEM $0.3, \mathrm{n}=10$ ). The difference between the two groups was not significant (unpaired $t$ test; $t=1.49 ; 0.1<P<0.2$ ). It was interesting to examine the curves of total CK release in order to determine whether the tendency towards 
higher enzyme release among treated patients could be accounted for by a 'washout' of enzyme activity resulting from improved perfusion of ischaemic myocardium (Roe and Starmer, 1975). This postulated mechanism could lead to a paradoxical increase in enzyme release without a concomitant increase in infarct size. However, when the proportion of total enzyme release which occurred during 12 hours after the start of therapeutic intervention was compared with that over a similar period in patients receiving normal saline, no difference was apparent.

An insufficient number of cases of anterior infarction was available for statistical analysis of enzyme release, the result in part of the fact that 3 of the 4 patients with anterior infarction who had cardiac arrest did so before total CK release could be determined; all of these patients were receiving glucose or glucose-insulin-potassium. Because of the apparently detrimental effect of glucose and glucose-insulin-potassium on the clinical status and the extent of enzyme release in these initial studies, detailed observations in larger numbers of patients were considered ethically unjustifiable.

\section{Discussion}

Our study has clearly shown that after acute myocardial infarction in man, glucose and glucoseinsulin-potassium improve left ventricular function as judged by increases in left ventricular stroke work index and cardiac index. These results are consistent with a positive inotropic action as has also been reported in patients with ischaemic heart failure and in experimental animals with anoxic myocardium (Sodi-Pollares et al., 1966). The mechanism of the inotropic effect of glucose and glucose-insulin-potassium is not, however, fully understood.

It has been postulated that augmentation of glucose supply to the heart enhances anaerobic glycolysis (Maroko et al., 1972; Majid et al., 1972; Austen et al., 1965), as indicated by studies which have shown increased myocardial glucose uptake after experimental coronary occlusion in dogs (Owen et al., 1969; Brachfeld and Scheuer, 1967). Such an action should produce an early change in cardiac function from the sudden increase in fuel supply to the ischaemic myocardium, and was the rationale for the timing of the haemodynamic measurements in the present study. Alternatively, improvement in myocardial function might result from a reduction in infarct size (Maroko et al., 1972). A change in cardiac function resulting from actual anatomical improvement, however, could

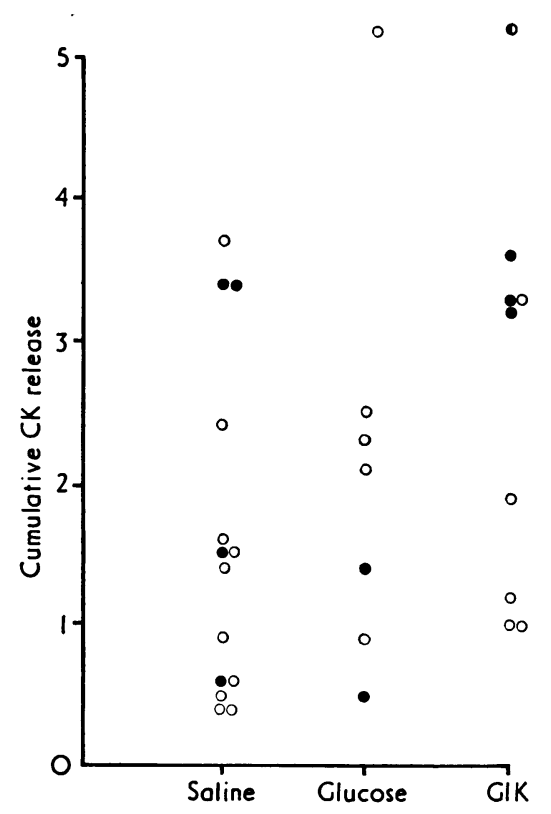

Fig. 4 Total creatine kinase (CK) release (IU/ml) in 30 patients receiving either saline, glucose, or glucose-insulin-potassium (GIK). Closed circles denote patients with anterior infarction; open circles, patients with inferior infarction; and the composite closed and open circle a patient with combined anterior and inferior infarction.

appear late and might not be shown by our haemodynamic procedure.

If the improvement in haemodynamics found in our study was the result of enhanced glucose utilisation, the fact that glucose-insulin-potassium and glucose infusions produced similar effects is of interest. It suggests either that the dose of insulin in our glucose-insulin-potassium infusion (based on Maroko et al., 1972) was inadequate, or that sufficient endogenous insulin was available in the patients given glucose alone to allow glucose uptake comparable with that in the glucose-insulinpotassium group, despite reports that intrinsic insulin secretion is suppressed after myocardial infarction in man (Allison et al., 1969; Taylor et al., 1969). Serum insulin levels were not measured in our patients since our main objectives were to investigate the effects of glucose infusions, with and without insulin, on infarct size and myocardial function after acute myocardial infarction. The finding of Lesch and colleagues (1974), however, suggests that serum insulin levels in our patients treated with glucose-insulin-potassium were sub-

* The method used for the calculation of total CK release is summarised in Fig. 3. 
stantially increased. Despite using a smaller dose of insulin than that employed in the present study, Lesch found that immunoreactive insulin in his subjects was increased 20 to 100 fold. Alternatively, it is also possible that in the presence of high glucose levels, as found in the present study, increased myocardial glycolysis could occur without insulin (Morgan et al., 1961; Weissler et al., 1968).

A further quite different possibility is that the stimulatory haemodynamic effects of glucose and glucose-insulin-potassium were unrelated to any myocardial metabolic effects, but were caused by an increase in blood volume after infusion of the hypertonic solutions. Though plasma volumes were not measured, this appears likely as the increase in left ventricular stroke work index which occurred in our patients was associated with a concomitant increase in left ventricular preload measured indirectly by the pulmonary artery end diastolic pressure, indicating that the inotropic effect was the result in part of the Frank-Starling mechanism. This could have resulted from diastolic stretching of the ventricles because of an increase in plasma volume after infusion of the hypertonic solutions. Hyperosmolar infusions are believed to have other salutary effects on the ischaemic myocardium in reducing cellular oedema and improving tissue perfusion (Leaf, 1973). The change in blood glucose levels suggests that osmolality must have increased by over $20 \mathrm{mosm} / \mathrm{kg} \mathrm{H}_{2} \mathrm{O}$ after intervention with glucose and glucose-insulin-potassium. Experimental and clinical studies have shown that an increase in osmolality of this order produces significant improvement in myocardial contractile function (Wildenthal et al., 1969; Willerson et al., 1973). Furthermore, hyperosmolar infusions have also been shown to cause sympathetically-mediated increases in heart rate and arterial pressure (Holland et al., 1959; Lasser et al., 1960), which were found in our subjects.

The failure of other workers (Most et al., 1972; Lesch et al., 1974) to show a stoichiometric relation between myocardial glucose uptake and lactate release during glucose-insulin-potassium infusion in man also argues against glucose-insulin-potassium and glucose having any stimulant effect on anaerobic glycolysis. The absence of such a relation has recently been confirmed in our own experimental laboratory, since we failed to show increased glucose uptake after glucose-insulin-potassium in the acutely ischaemic myocardium after ligation of the left anterior descending coronary artery in dogs (Heng et al., 1976). Moreover, studies by Rovetto and colleagues (Rovetto et al., 1973) in the ischaemic rat heart have shown that, during ischaemia, glycolytic flux is reduced and cannot be stimulated by glucose or glucose-insulin-potassium. This was attributed to an increase in intracellular acidity resulting from the accumulation of lactate in the poorly perfused ischaemic myocardium.

Although the present study was prompted by reports that glucose-insulin-potassium and glucose have a protective effect on the myocardium in experimental infarction (Maroko et al., 1972), our results indicate that intervention with these regimens in man may enhance myocardial oxygen demand by producing increases in left ventricular stroke work index, heart rate, and mean aortic pressure (Sarnoff and Braunwald, 1962). These changes, however, may not be necessarily detrimental, as the ultimate effect on infarct size will depend on the balance between the increase in myocardial oxygen demand and that of improved coronary perfusion resulting from increased arterial pressure (Maroko et al., 1971). It was hoped that definitive answers to these questions could be provided by the estimation of infarct size as measured by enzyme release. These measurements did not reveal a favourable trend in the alteration of infarct size; indeed there was a tendency in patients with inferior infarcts for total CK release to be greater among patients given glucose or glucoseinsulin-potassium than among those given saline. This tendency, however, did not reach statistical significance because of the wide range of enzyme release which occurred. Though we tried to select a homogeneous group of patients on clinical criteria, the size of infarcts varied up to tenfold, and the range from 4 to 14 hours from the time of onset to intervention added a further variable. Thus, in order to show a difference in infarct size between two groups of patients, the number studied would have to be large, and it might be necessary for intervention to be made within a shorter period such as 4 to 6 hours after the onset. We considered it ethically unjustifiable to expand the present study further, however, as we were concerned not only with the apparently unfavourable trends with enzyme release after glucose and glucose-insulinpotassium infusions, but also with the fact that 3 treated patients had cardiac arrests during infusion, compared with no complications in the control group. Though the number of patients required to permit statistically significant conclusions may be much less with the curve-fitting procedure suggested by Shell and colleagues (Shell et al., 1973), the necessity to withhold therapeutic intervention for several hours after admission is a serious objection to this technique.

Our findings of a negative and possibly deleterious effect of glucose and glucose-insulin-potassium are in agreement with those of Reduto et al. (1974) who 
infused a smaller dose of glucose-insulin-potassium later after the onset of infarction than was the case in our study. They may also be complementary to those of Lesch et al. (1974) who noted signs of enhanced ischaemia after glucose-insulin-potassium in 5 of 8 patients with angina pectoris subjected to atrial pacing stress. Our data and those of Lesch et al. (1974) do not nevertheless exclude the possibility that glucose and glucose-insulin-potassium administration in cardiogenic shock may be beneficial.

\section{References}

Allison, S. P., Chamberlain, M. J., and Hinton, P. (1969). Intravenous glucose tolerance, insulin, glucose, and free fatty acid levels after myocardial infarction. British Medical fournal, 4, 776-778.

Austen, W. G., Greenberg, J. J., and Piccinini, J. C. (1965). Myocardial function and contractile force affected by glucose loading of the heart during anoxia. Surgery, 57, 839-845.

Ballard, F. B., Danforth, W. H., Naegle, S., and Bing, R. J. (1960). Myocardial metabolism of fatty acids. Fournal of Clinical Investigation, 39, 717-723.

Brachfeld, N. (1973). The glucose-insulin-potassium (GIK) regimen in the treatment of myocardial ischaemia. Circulation, 48, 459-462.

Brachfeld, N., and Scheuer, J. (1967). Metabolism of glucose by the ischaemic dog heart. American fournal of Physiology, 212, 603-606.

Crexells, C., Chatteriee, K., Forrester, J. S., Dikshit, K., and Swan, H. J. C. (1973). Optimal level of filling pressure in the left side of the heart in acute myocardial infarction. New England Fournal of Medicine, 289, 1263-1266.

De Leiris, J., Opie, L. H., and Lubbe, W. F. (1975). Effects of free fatty acid and glucose on enzyme release in experimental myocardial infarction. Nature, 253, 746-747.

Evans, J. R. (1964). Importance of fatty acid in myocardial metabolism. Circulation Research, 15, Suppl. II, 96-106.

Heng, M. K., Singh, B. N., Peter, T., Nisbet, H. D., and Norris, R. M. (1976). The effects of glucose-insulinpotassium in experimental myocardial infarction in the dog. Submitted for publication.

Holland, R. C., Sundsten, J. W., and Sawyer, C. H. (1959). Effects of intracarotid injections of hypertonic solutions on arterial pressure in the rabbit. Circulation Research, 7, 712-720.

Lasser, R. P., Schoenfeld, M. R., Allen, D. F., and Friedberg, C. K. (1960). Reflex circulatory effects elicited by hypertonic and hypotonic solutions injected into femoral and brachial arteries of dogs. Circulation Reseach, 8, 913-919.

Leaf, A. (1973). Cell swelling. A factor in ischemic tissue injury. Circulation, 48, 455-458.

Lesch, M., Teichholz, L. E., Soeldner, J. S., and Gorlin, R. (1974). Ineffectiveness of glucose, potassium and insulin infusion during pacing stress in chronic ischaemic heart disease. Circulation, 49, 1028-1037.

Lown, B., Fakhro, A. M., Hiood, W. B., and Thorn, G. W. (1967). The coronary-care unit. Fournal of the American Medical Association, 199, 188-198.

Majid, P. A., Sharma, B., Meeran, M. K. M., and Taylor, S. H. (1972). Insulin and glucose in the treatment of heart failure. Lancet, 2, 937-941.

Maroko, P. R., Kjekshus, J. K., Sobel, B. E., Watanabe, T., Covell, J. W., Ross, J., and Braunwald, E. (1971). Factors influencing infarct size following experimental coronary artery occlusions. Circulation, 43, 67-82.

Maroko, P. R., Libby, P., Sobel, B. E., Bloor, C. M., Sybers, H. D., Shell, W. E., Covell, J. W., and Braunwald, E. (1972). Effect of glucose-insulin-potassium infusion on myocardial infarction following experimental coronary artery occlusion. Circulation, 45, 1160-1175.

Medical Research Council Working Party on the Treatment of Myocardial Infarction (1968). Potassium, glucose and insulin treatment for acute myocardial infarction. Lancet, 2, 1355-1360.

Mittra, B. (1965). Potassium, glucose, insulin in treatment of myocardial infarction. Lancet, 2, 607-609.

Morgan, H. E., Henderson, M. J., Regan, D. M., and Park, C. R. (1961). Regulation of glucose uptake in muscle. I. The effects of insulin and anoxia on glucose transport and phosphorylation in the isolated, perfused heart of normal rats. Fournal of Biological Chemistry, 236, 253-261.

Most, A. S., Gorlin, R., and Soeldner, J. S. (1972). Glucose extraction by the human myocardium during pacing stress. Circulation, 45, 92-96.

Norris, R. M., Whitlock, R. M. L., Barratt-Boyes, C., and Small, C. W. (1975). Clinical measurement of myocardial infarct size. Modification of a method for the estimation of total creatine phosphokinase release after myocardial infarction. Circulation, 51, 614-620.

Owen, P., Thomas, M., and Opie, L. (1969). Relative changes in free-fatty-acid and glucose utilisation by ischaemic myocardium after coronary artery occlusion. Lancet, 1, 1187-1190.

Reduto, L., Gulotta, S., and Morrison, J. (1974). Ineffectiveness of glucose-insulin-potassium infusion on ischemic myocardium. Clinical Research, 22, 685A.

Roe, C. R., and Starmer, C. F. (1975). A sensitivity analysis of enzymatic estimation of infarct size. Circulation, 52, 1-5.

Rosalki, S. B. (1967). An improved procedure for serum creatine phosphokinase determination. Fournal of Laboratory and Clinical Medicine, 69, 696-705.

Rovetto, M. J., Whitmer, J. T., and Neely, J. R. (1973). Comparison of the effects of anoxia and whole heart ischemia on carbohydrate utilization in isolated working rat hearts. Circulation Research, 32, 699-711.

Sarnoff, S. J., and Braunwald, E. (1962). Hemodynamic determinants of myocardial oxygen consumption. In Cardiovascular Functions, p. 24. Ed. by A. A. Luisada. McGraw-Hill, New York.

Shell, W. E., Lavelle, J. F., Covell, J. W., and Sobel, B. E. (1973). Early estimation of myocardial damage in conscious dogs and patients with evolving acute myocardial infarction. Fournal of Clinical Investigation, 52, 2579-2590.

Sobel, B. E., Bresnahan, G. F., Shell, W. E., and Yoder, R. D. (1972). Estimation of infarct size in man and its relation to prognosis. Circulation, 46, 640-648.

Sodi-Pallares, D., Bisteni, A., Medrano, G. A., De Micheli, A., Ponce de León, J., Calva, E., Fishleder, B. L., Testelli, M. R., and Miller, B. L. (1966). The polarising treatment in cardiovascular conditions. Experimental basis and clinical applications. In Electrolytes and Cardiovascular Diseases, p. 198. Ed. by E. Bajusz. S. Karger, A.G., Basel.

Taylor, S. H., Saxton, C., Majid, P. A., Dykes, J. R. W., Ghosh, P., and Stoker, J. B. (1969). Insulin secretion following myocardial infarction with particular respect to the pathogenesis of cardiogenic shock. Lancet, 2, 1373-1378.

Weissler, A. M., Kruger, F. A., Baba, N., Scarpelli, D. G., Leighton, R. F., Gallimore, J. K. (1968). Role of anaerobic metabolism in the preservation of functional capacity and structure of anoxic myocardium. Fournal of Clinical Investigation, 47, 403-416.

Wildenthal, K., Mierzwiak, D. S., and Mitchell, J. H. (1969). 
Acute effects of increased serum osmolality on left ventricular performance. American fournal of Physiology, 216, 898-904.

Willerson, J. T., Curry, G. C., Atkins, J. M., Wildenthal, K., and Horwitz, L. D. (1973). The influence of hypertonic mannitol on hemodynamics and coronary blood flow in patients. Circulation, 47-48, Suppl. IV-7.

Requests for reprints to Dr. R. M. Norris, Coronary-Care Unit, Green Lane Hospital, Green Lane West, Auckland 3, New Zealand. 